\title{
Tyrosine phosphorylation of platelet derived growth factor $\beta$ receptors in coronary artery lesions: implications for vascular remodelling after directional coronary atherectomy and unstable angina pectoris
}

\author{
J Abe, J Deguchi, Y Takuwa, K Hara, Y Ikari, T Tamura, M Ohno, K Kurokawa
}

\begin{abstract}
Background-Growth factors such as platelet derived growth factor (PDGF) have been postulated to be important mediators of neointimal proliferation observed in atherosclerotic plaques and restenotic lesions following coronary interventions. Binding of PDGF to its receptor results in intrinsic receptor tyrosine kinase activation and subsequent cellular migration, proliferation, and vascular contraction.

Aims-To investigate whether the concentration of PDGF $\beta$ receptor tyrosine phosphorylation obtained from directional coronary atherectomy (DCA) samples correlate with atherosclerotic plaque burden, the ability of diseased vessels to remodel, coronary risk factors, and clinical events.
\end{abstract}

Methods-DCA samples from 59 patients and 15 non-atherosclerotic left internal thoracic arteries (LITA) were analysed for PDGF $\beta$ receptor tyrosine phosphorylation content by receptor immunoprecipitation and antiphosphotyrosine western blot. The amount of PDGF $\beta$ receptor phosphorylation was analysed in relation to angiographic follow up data and clinical variables.

Results-PDGF $\beta$ receptor tyrosine phosphorylation in the $59 \mathrm{DCA}$ samples was greater than in the 15 non-atherosclerotic LITA (mean (SD) $0.84(0.67) v 0.17(0.08)$ over a control standard, $p<0.0001)$. As evaluated by stepwise regression analysis, incorporation of both PDGF $\beta$ receptor tyrosine phosphorylation and immediate gain correlated strongly (adjusted $r^{2}=0.579$ ) with late loss, although PDGF $\beta$ receptor tyramine phosphorylation alone correlated poorly with late loss. Multivariate regression analysis of coronary risk factors and clinical events revealed unstable angina as the most significant correlate of PDGF $\beta$ receptor tyrosine phosphorylation (F value 20.009, p $<0.0001$ ).

Conclusions-PDGF $\beta$ receptor tyrosine phosphorylation in atherosclerotic lesions is increased compared with nonatherosclerotic arterial tissues. The association of PDGF $\beta$ receptor tyrosine phosphorylation with immediate gain strongly correlates with vascular remodelling. PDGF $\beta$ receptor tyrosine phosphorylation correlates with unstable angina pectoris.

(Heart 1998;79:400-406)

Keywords: PDGF receptors; atherosclerosis; directional coronary atherectomy; restenosis

The development of coronary artery restenosis continues to be a major limitation of percutaneous transluminal coronary angioplasty (PTCA). ${ }^{1}$ Clinical and basic research have implicated several important factors in the pathogenesis of restenosis including: smooth muscle proliferation, thrombus formation, overproduction of extracellular matrix, progression of the underlying atherosclerotic lesion, and failure of vessel remodelling. ${ }^{23}$ Of note, intimal hyperplasia due to smooth muscle proliferation appears to be a common and important event in the process of restenosis..$^{3-6}$ Several growth factors have been shown to stimulate vascular smooth muscle cell proliferation and may be involved in restenosis: platelet derived growth factor (PDGF), ${ }^{7}$ fibroblast growth factor, ${ }^{8}$ transforming growth factor $\beta,{ }^{9}$ angiotensin $\mathrm{II}^{10}{ }^{10}$ and insulin-like growth factor I. ${ }^{11}$ Because of its potent activity as a mitogen and chemoattractant as well as its presence in neointimal tissues and atherosclerotic plaques, PDGF has been postulated to be an important factor responsible for vascular smooth muscle proliferation. ${ }^{12}{ }^{13}$ In addition, PDGF stimulates vascular contraction, and may contribute to the enhanced vasoreactivity of certain atherosclerotic vessels. ${ }^{14}$

Several groups have studied the expression of the PDGF receptor and its ligand within human atherosclerotic tissue. Using in situ hybridisation, PDGF $\mathrm{A}$ and $\mathrm{B}$ chain mRNAs were found in mesenchymal appearing intimal cells and endothelial cells, respectively. ${ }^{13}$ However, Barrett et $a l^{15}$ reported that PDGF A and $B$ chains were also highly expressed in non-atherosclerotic artery, suggesting that PDGF $\mathrm{A}$ and $\mathrm{B}$ chain $\mathrm{mRNA}$ expression did not necessarily cause smooth muscle cell proliferation in atherosclerosis. ${ }^{15}$ In contrast, both $\alpha$ and $\beta$ receptors of PDGF are localised predominantly in the atherosclerotic plaque intima, ${ }^{13}$ while in vessels of normal tissues PDGF $\beta$ receptors were not expressed or only 
Table 1 Tyrosine phosphorylation of PDGF $\beta$ receptor in non-atherosclerotic arterial segments of different sizes

\begin{tabular}{llllll}
\hline Sample & $\begin{array}{l}\text { Wet weight } \\
(\mathrm{mg})\end{array}$ & $\begin{array}{l}\text { Protein content } \\
(\mu \mathrm{g})\end{array}$ & $\begin{array}{l}\text { Raw value } \\
(\mathrm{OD})\end{array}$ & $\begin{array}{l}\text { Value per } 10 \mathrm{mg} \\
\text { tissue }\end{array}$ & $\begin{array}{l}\text { Value per } 100 \mu \mathrm{g} \\
\text { protein }\end{array}$ \\
\hline 1 & 11.5 & 126 & 0.014 & 0.0122 & 0.0111 \\
2 & 19.7 & 208 & 0.022 & 0.0112 & 0.0106 \\
3 & 23.8 & 286 & 0.033 & 0.0138 & 0.0115 \\
\hline
\end{tabular}

Three segments were cut from a gastroepiploic artery, weighed, homogenised, assayed for protein content, and analysed for tyrosine phosphorylation of PDGF $\beta$ receptor. OD, optical density.

minimally expressed. ${ }^{16}$ However, the activity of PDGF in vivo in atherosclerotic plaques is unknown. PDGF exerts its biological effects through high affinity interactions with two subtypes ( $\alpha$ and $\beta$ ) of PDGF receptors. PDGF A chain interacts only with PDGF $\alpha$ receptor, while PDGF A chain interacts with $\alpha$ and $\beta$ receptors. ${ }^{17}{ }^{18}$ PDGF $\mathrm{B}$ chain is more potent than PDGF $B$ chain as a mitogen and chemoattractant for vascular smooth muscle cells via its interaction with the PDGF $\beta$ receptor. ${ }^{19}$ The activation of the intrinsic tyrosine kinase activity of the PDGF receptor by PDGF ligand results in receptor autophosphorylation at critical tyrosine residues and activation of second messenger pathways necessary for the induction of gene expression, DNA synthesis, mitogenesis, and vascular contraction. ${ }^{14} 17$ Therefore, to investigate the role of PDGF in atherosclerosis and vascular stenosis after percutaneous transluminal coronary angioplasty (PTCA), we hypothesised that the measurement of the extent of PDGF $\beta$ receptor tyrosine phosphorylation in cells and tissues should provide important information about the PDGF $\beta$ receptor and its activation in vivo. By evaluating tyrosine phosphorylation of PDGF receptors, we recently observed that in a rat carotid balloon injury model, the activation of PDGF receptors correlated with neointima formation. ${ }^{20}$

The use of directional coronary atherectomy (DCA) has allowed investigators to sample tissue from human intravascular plaques. ${ }^{21} \mathrm{We}$ measured the extent of tyrosine phosphorylation of PDGF $\beta$ receptor in atherectomy samples, and analysed the relation between the extent of tyrosine phosphorylation of PDGF $\beta$ receptor in atherectomy specimens and the degree of subsequent vascular remodelling, as well as clinical variables.

\section{Methods}

PATIENTS AND ATHERECTOMY PROCEDURES

Coronary atherectomy specimens were obtained with the Simpson AtheroCath (Devices for Vascular Interventions, Redwood, California, USA $)^{42}$ from 59 patients anatomically and clinically suitable for the procedure between 10 October 1993 and 6 September 1994 at Mitsui Memorial Hospital. Patients

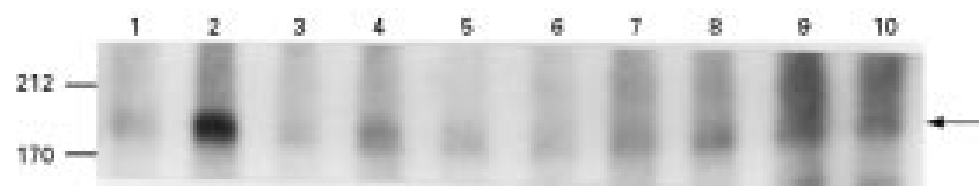

Figure 1 Antiphosphotyrosine western blot of $10 \mathrm{DCA}$ specimens. Arrowhead indicates the position of PDGF $\beta$ receptor. The numbers on the left are molecular weights in $k D a$. who showed enzymatic or electrocardiographic evidence of acute myocardial infarction were excluded. Premedication with aspirin $(325 \mathrm{mg} /$ day) was started 24 hours before the procedure, and a $10000 \mathrm{U}$ bolus of heparin was given after insertion of the $10 \mathrm{~F}$ arterial sheath and supplemented as needed to maintain the activated clotting time at $>250$ seconds. Approximately $20 \mathrm{mg}$ of tissue were removed in each procedure; one half of which was used for determination of tyrosine phosphorylation of PDGF $\beta$ receptor, and the other for light microscopy. Before DCA was performed, we explained to the patients the objectives, procedures, protocols, and possible complications involved. Informed written consent was obtained from all patients who underwent DCA. The study protocol had been approved by our institutional review board. As a normal control, a segment of internal thoracic artery was obtained from 15 patients who underwent coronary bypass graft operation. None of the internal thoracic arteries had significant intimal thickening by microscopic examination.

DETERMINATION OF TYROSINE PHOSPHORYLATION OF PDGF RECEPTOR

Each atherectomy specimen was removed promptly from the atherectomy collection chamber and immediately stored at $-80^{\circ} \mathrm{C}$. Surgically resected internal thoracic arteries were transported at $4^{\circ} \mathrm{C}$ to the laboratory and immediately processed for immunoprecipitation. Specimens were homogenised at $4^{\circ} \mathrm{C}$ in $300 \mathrm{ml}$ of a buffer containing $50 \mathrm{mM}$ Tris- $\mathrm{HCl}$ $\mathrm{pH} 8.0,120 \mathrm{mmol} / \mathrm{l} \mathrm{NaCl}, 0.5 \%$ NonidetP $40,100 \mathrm{mmol} / 1 \mathrm{NaF}, 1 \mathrm{mmol} / 1 \mathrm{Na}_{3} \mathrm{VO}_{4}, 0.1 \%$ sodium dodecylsulphate (SDS), $2 \mathrm{mmol} / 1$ EGTA, $80 \mathrm{mg} / \mathrm{ml}$ each of leupeptin and aprotinin, and $0.6 \mathrm{mmol} / \mathrm{l}$ phenylmethylsulphonyl fluoride. The homogenate was cleared by centrifugation at $10000 \times g$ for five minutes at $4^{\circ} \mathrm{C}$. After an aliquot of the supernatant was used for the determination of protein content, $250 \mu \mathrm{g}$ of cell protein per sample was subjected to immunoprecipitation using antihuman PDGF $\beta$ receptor antibody (UBI, Lake Placid, New York, USA). The immune complex was collected by incubation with protein A sepharose (Pharmacia). The immunoprecipitates were subjected to $8 \%$ SDS-polyacrylamide gel electrophoresis (SDS-PAGE) under a reducing condition. The separated proteins were electrotransferred to an Immobilon-P membrane (Millipore) at $160 \mathrm{~mA}$ for 50 minutes. Nonspecific binding of antibodies was blocked by incubating a membrane with 3\% (wt/vol) bovine serum albumin in Tris buffered saline $(137 \mathrm{mmol} / 1 \mathrm{NaCl}, 20 \mathrm{mmol} / \mathrm{l}$ Tris- $\mathrm{HCl}$, $\mathrm{pH}$ 7.6). The membrane was probed with antiphosphotyrosine antibody (clone 4G10) (UBI), and visualised by the ECL chemiluminescence method as described previously. ${ }^{24}$ The extent of PDGF $\beta$ receptor phosphorylation was measured by a scanning densitometer (Quantity One; PDI Inc, New York, USA). The background could be subtracted easily and objectively using the rolling method software analysis provided with Quantity One. The PDGF $\beta$ receptor phosphorylation value of 


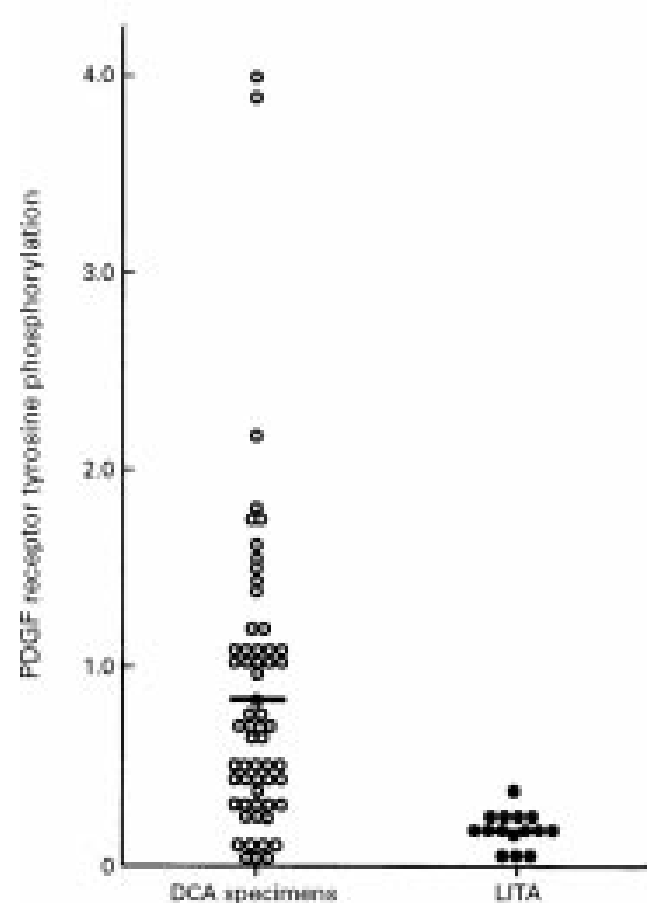

Figure 2 Tyrosine phosphorylation levels of PDGF $\beta$ receptor in 59 atherectomy specimens and 15

non-atherosclerotic left internal thoracic arteries (LITA). The bars indicate means. There was a significant difference $(p<0.0001)$ between DCA specimens and LITA.

atherectomy specimens and left internal thoracic arteries was expressed as the ratio of densitometric value (OD) of the specimen to the control standard value (OD) of PDGF $\beta$ receptor tyrosine phosphorylation of PDGF $\mathrm{B}$ stimulated human fibroblasts.

\section{ANGIOGRAPHIC ANALYSIS}

Follow up angiography was performed on symptom free patients three to six months after DCA. However, patients with chest pain or positive exercise test underwent angiography earlier. Angiographic analysis was done with a computer assisted electronic caliper system (Cathex Coronary Artery Measurement System; Cathex Inc, Tokyo, Japan). ${ }^{25}$ Measurements were made in a single projection using a frame that showed the clearest and severest stenosis. Whenever possible, all three measurements (before DCA, immediately after DCA, and at follow up) were performed with the same camera angulation to allow a more precise comparison. The amount of immediate gain was defined as the difference in luminal diameter at the lesion before and immediately after atherectomy. The amount of late loss was defined as the absolute change in luminal diameter immediately after atherectomy and at follow up. Restenosis was defined as stenosis of more than $50 \%$ at the DCA site at the time of follow up angiography.

STATISTICAL ANALYSIS

Data are reported as mean (SD). Statistical analysis was performed with the StatView 4.0 package (ABACUS Concepts, Berkeley, California, USA). Differences were analysed with unpaired two-tailed Student's $t$ test, Welch's $t$ test, Mann-Whitney test, or by linear regression analysis, as appropriate. Independent determinants of the linear outcomes of interest were constructed by simple and multivariate regression analyses. The final model that contained the independent determinants in each analysis was described as a linear combination of intercept and $\beta$ terms. A p value of $<0.05$ was considered statistically significant.

The relation between the extent of tyrosine phosphorylation of PDGF $\beta$ receptor and clinical variables were analysed by simple and stepwise regression analysis (a forward selection procedure) as described previously. ${ }^{25}$ The variables analysed were risk factors for coronary artery disease-sex, hypertension (blood pressure that required treatment before DCA), diabetes mellitus, smoking, family history of coronary artery disease, obesity (> 20\% ideal body weight), restenotic lesions, unstable angina, raised serum cholesterol concentration, and age at the time of DCA. Any variable with a partial $F$ value of $\geqslant 4.0$ was included in the regression analysis, and any previously entered variables with a partial $\mathrm{F}$ value of $<4.0$ were removed from the analysis.

\section{Results}

BASELINE CLINICAL CHARACTERISTICS OF THE STUDY PATIENTS

The study population comprised 59 patients (44 men and 15 women) with a mean age of 62 years. Twenty patients presented with clinically unstable angina. However, their condition stabilised with medical treatment by the time they were subjected to the study atherectomy. The remaining 39 patients had stable angina. A single lesion from each patient was used for the study. Of the 59 atherectomy specimens obtained, 48 were from the left anterior descending coronary artery, one from the left circumflex coronary artery, seven from the right coronary artery, two from protected left main trunks, and one from a saphenous vein graft. Thirty of the specimens were from primary lesions to which a percutaneous coronary intervention was attempted for the first time. The other 29 specimens were from restenotic lesions. The average interval between the prior intervention and the study atherectomy in the restenosis lesion group was 4.5 months (range $2-8$ ). Seven of 29 restenotic lesions developed after previous DCA, the other 22 after conventional balloon angioplasty.

\section{ANGIOGRAPHIC OBSERVATIONS}

The mean (SD) angiographic severity (percentage reduction in diameter) of target lesions was $66(13) \%$, and the mean reference diameter was $2.85(0.58) \mathrm{mm}$. Both device success and lesion success were obtained in all patients, resulting in a residual stenosis of $-3(21) \%$. The mean immediate gain of lumen diameter in these patients was $2.00(0.74) \mathrm{mm}$ (range 0.75-3.56). Angiographic follow up data were obtained for 49 patients $(83 \%)$ a mean of 121 days after the study atherectomy (range 79-185). Fifteen of the 49 vessels showed restenosis (stenosis of more than $50 \%$ ) at the site of atherectomy, with the average ratio of late loss 

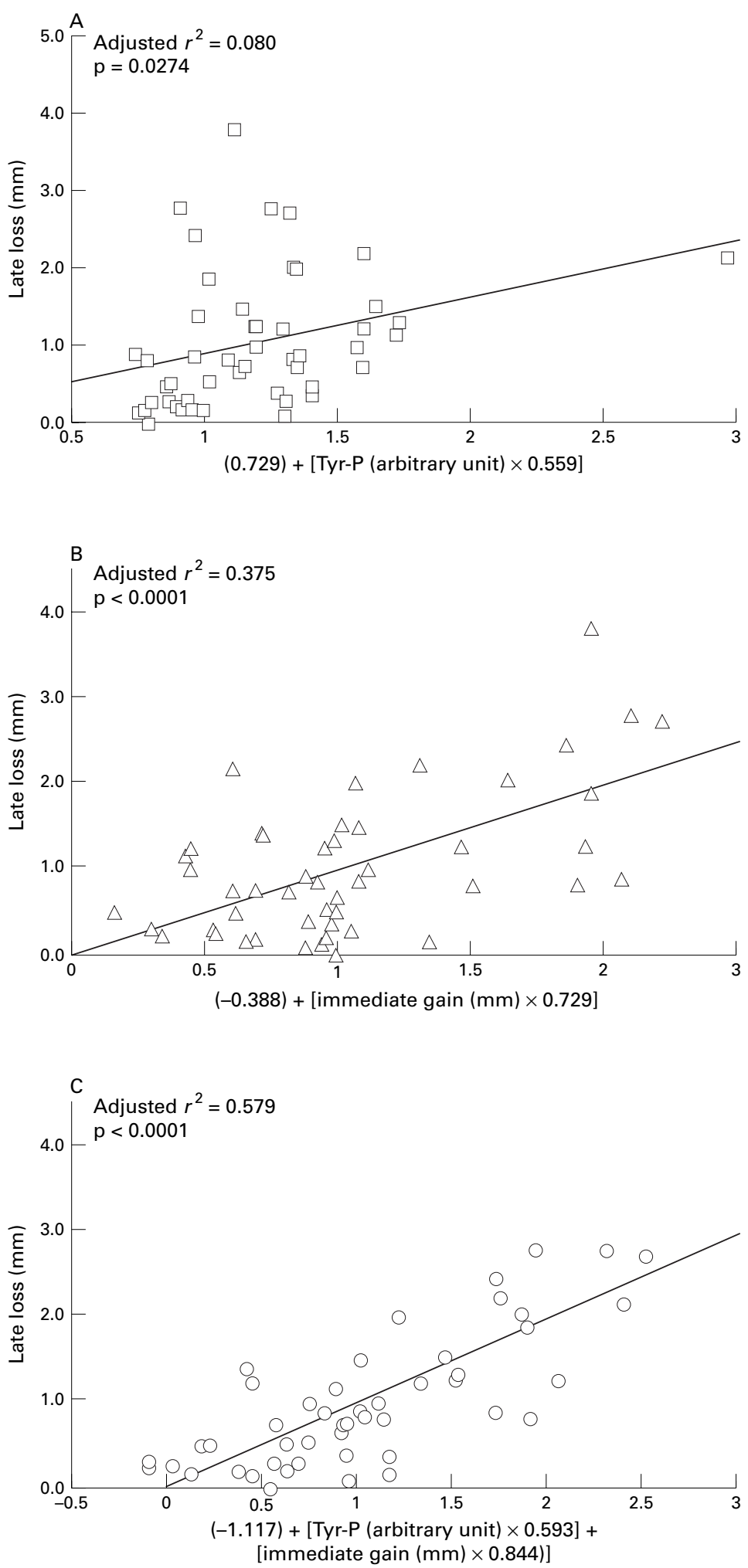

Figure 3 Simple and multivariate regression analyses of the amount of late loss of lumen diameter in relation to $(A)$ the extent of tyrosine phosphorylation $(T y r-P),(B)$ immediate gain, and $(C)$ immediate gain and Tyr-P.

to immediate gain of lumen diameter (the loss index) of 0.93 (0.23). The 34 patients without restenosis had an average loss index of $0.34(0.20)$. All 15 patients with restenosis underwent an additional percutaneous coronary intervention; the remaining 34 patients without restenosis were treated with drugs.
ANALYSIS OF TYROSINE PHOSPHORYLATION OF PDGF $\beta$ RECEPTOR IN DCA SPECIMENS

Attempts to evaluate PDGF $\beta$ receptor protein quantitatively in DCA specimens were inconclusive due to the limited quantity of protein present in DCA specimens. Therefore, we focused on the tyrosine phosphorylation of PDGF $\beta$ receptor, which more accurately reflects PDGF $\beta$ receptor "activity".

To evaluate whether determination of PDGF $\beta$ receptor tyrosine phosphorylation in arterial tissues can be performed quantitatively, we measured tyrosine phosphorylation of human non-atherosclerotic artery (gastroepiploic artery) by immunoprecipitation of PDGF $\beta$ receptors from arterial homogenates and western blotting using antiphosphotyrosine antibody. Tyrosine phosphorylation of PDGF $\beta$ receptor in three arterial segments of different sizes were similar when the values were expressed as an optic density value per a constant tissue weight or per a constant protein amount, indicating that phosphorylation of PDGF $\beta$ receptors can be measured quantitatively (table 2 ).

A significant amount of tyrosine phosphorylation of PDGF $\beta$ receptor was detected in all of the DCA specimens and control internal thoracic arteries. As shown in a western blot of 10 representative atherectomy specimens (fig 1 ), the extent of tyrosine phosphorylation of PDGF $\beta$ receptor was variable (range 0.053.99) (fig 2). The mean value of PDGF $\beta$ receptor phosphorylation for 59 samples was significantly greater in the DCA specimens than in non-atherosclerotic internal thoracic arteries $(0.84 \quad(0.67) \quad v \quad 0.17 \quad(0.08)$, $\mathrm{p}<0.0001)$. These results indicate that in stenotic lesions of coronary arteries, activated PDGF $\beta$ receptors are present in varying amounts.

Of the 49 patients who underwent follow up angiography, the extent of PDGF $\beta$ receptor tyrosine phosphorylation was significantly greater in the 15 individuals that developed restenosis than in the 34 subjects who did not (1.31 (0.87) $v 0.63(0.43) ; \mathrm{p}<0.02)$. In the 49 patients with follow up angiography, the extent of tyrosine phosphorylation of PDGF $\beta$ receptor correlated with three measures of restenosis: the loss index ratio of luminal diameter $(r=0.664, \mathrm{p}<0.0001)$, the amount of late loss of lumen diameter $(r=0.315, \mathrm{p}=0.0269)$, and percentage stenosis $(r=0.499$, $\mathrm{p}=0.0002)$. There was no significant difference in the tyrosine phosphorylation of PDGF $\beta$ receptor between specimens from 30 primary lesions and from 29 restenotic lesions. In the present study, however, immediate gain was not correlated with PDGF $\beta$ receptor tyrosine phosphorylation $(r=0.201, \mathrm{p}=0.17)$, indicating that the good correlation of the loss index ratio with PDGF receptor phosphorylation is not due to the presence of immediate gain in the loss index ratio.

Previous studies revealed that the amount of late loss of luminal diameter observed on angiography is strongly influenced by the immediate gain of lumen diameter produced by coronary interventions. ${ }^{12627}$ These observations may 
Table 2 Simple and stepwise regression analysis of the relations between the extent of $P D G F$ receptor tyrosyl phosphorylation and clinical variables

\begin{tabular}{|c|c|c|c|c|c|}
\hline Clinical variables & $\beta$ & $S E$ & Std coeff & F value & $p$ value \\
\hline \multicolumn{6}{|l|}{ Simple regression analysis } \\
\hline Male sex & 0.447 & 0.234 & 0.246 & 3.669 & NS \\
\hline Age & -0.030 & 0.009 & -0.419 & 11.736 & 0.0012 \\
\hline Restenosis lesion & -0.259 & 0.203 & -0.166 & 1.624 & NS \\
\hline Diabetes mellitus & -0.295 & 0.211 & -0.183 & -1.402 & NS \\
\hline Tobacco use & 0.428 & 0.202 & 0.269 & 4.459 & 0.0391 \\
\hline Unstable angina & 0.816 & 0.188 & 0.499 & 18.893 & $<0.0001$ \\
\hline Family history of coronary artery disease & 0.327 & 0.260 & 0.165 & 1.590 & NS \\
\hline Serum cholesterol $(\mathrm{mg} / \mathrm{dl})$ & -0.006 & -0.003 & -0.279 & 4.148 & 0.0471 \\
\hline Obesity (> 20\% ideal weight) & 0.014 & 0.219 & 0.008 & 0.004 & NS \\
\hline Hypertension & 0.056 & 0.206 & 0.036 & 0.073 & NS \\
\hline \multicolumn{6}{|c|}{ Stepwise regression analysis $(\mathrm{F}$ value $=12.14, \mathrm{p}<0.0001)$} \\
\hline Unstable angina & 0.760 & 0.169 & 0.535 & 20.099 & \\
\hline Serum cholesterol (mg/dl) & -0.005 & 0.003 & -0.241 & 4.097 & \\
\hline
\end{tabular}

For the simple regression analysis of PDGF $\beta$ receptor tyrosyl phosphorylation: tyrosyl phosphorylation (arbitrary units) $=$ intercept $+($ variable $\times \beta)$.

Intercept $=1.595$; adjusted $\mathrm{R}^{2}=0.317$.

$\beta, \beta$ coefficient for linear regression model; SE, standard error; Std coeff, standardised regression coefficient.

explain the above finding in the present study that the extent of PDGF $\beta$ receptor phosphorylation more strongly correlated with the loss index (a measure that corrects for differences in immediate gain of lumen diameter after DCA) than with the amount of late loss of lumen diameter. To evaluate further the influence of the extent of PDGF $\beta$ receptor tyrosine phosphorylation and the immediate gain of lumen diameter on vascular remodelling, we analysed the relation between late loss and the combined variable of immediate gain and PDGF $\beta$ receptor tyrosine phosphorylation after atherectomy by employing simple and multivariate regression analysis. The extent of tyrosine phosphorylation of PDGF $\beta$ receptor correlated poorly with the amount of late loss

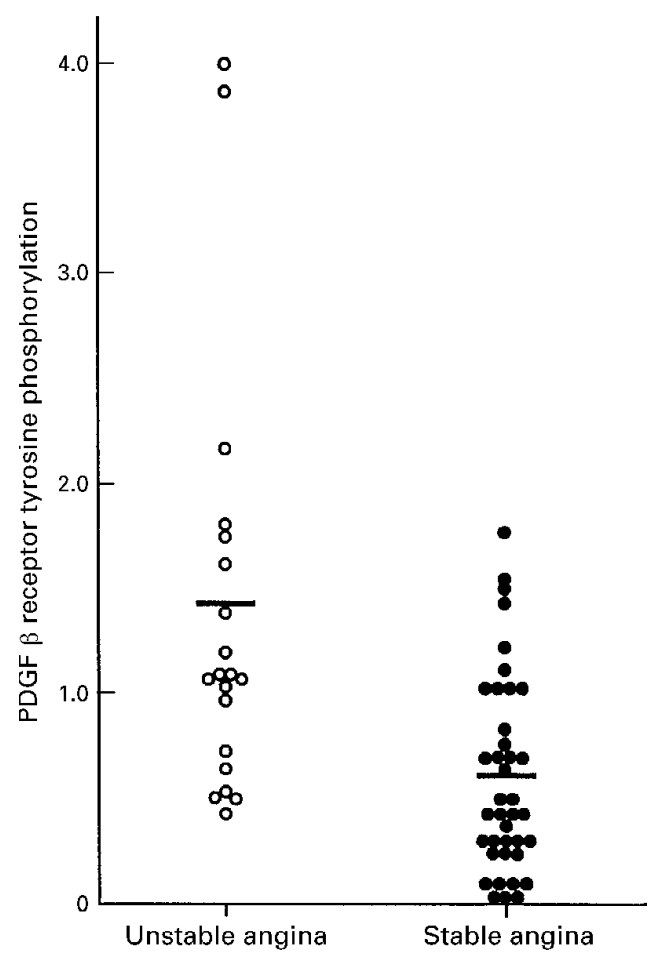

Figure 4 Tyrosine phosphorylation levels of PDGF $\beta$ receptor in 20 specimens from patients with unstable angina and 39 patients with stable angina. The bars indicate means. There was a significant difference $(p<0.002)$ between the two groups. of lumen diameter (adjusted $\mathrm{R}^{2}=0.080$ ) in the 49 patients as evaluated by simple regression analysis (fig 3A). The amount of immediate gain of lumen diameter after DCA also correlated better with late loss of lumen diameter (adjusted $\mathrm{R}^{2}=0.375$ ) than PDGF $\beta$ receptor tyrosine phosphorylation (fig 3B), which confirms previous observations. ${ }^{26}{ }^{27}$ The combination of the extent of PDGF $\beta$ receptor phosphorylation and the amount of immediate gain in lumen diameter even strongly correlated (adjusted $R^{2}=0.579$ ) with the extent of late loss of lumen diameter as evaluated by multivariate regression analysis (fig $3 \mathrm{C}$ ). Thus, patients with both a high level of PDGF $\beta$ receptor tyrosine phosphorylation and a large immediate gain at the time of initial atherectomy had a greater degree of late loss after atherectomy than did patients with one or none of these factors.

RELATION OF CLINICAL VARIABLES TO THE EXTENT OF PDGF $\beta$ RECEPTOR PHOSPHORYLATION IN DCA SPECIMENS

Linear regression analysis techniques were used to investigate which clinical variables are associated with tyrosine phosphorylation of PDGF $\beta$ receptor (table 2). Simple regression analysis revealed significant correlations between the extent of PDGF $\beta$ receptor phosphorylation and unstable angina $(\mathrm{p}<0.0001)$, age $(p=0.0012)$, and tobacco use $(p=0.0391)$. Stepwise regression analysis revealed unstable angina and cholesterol as significant independent variables (table 2). On the basis of the standardised regression coefficients, the strongest determinant of the extent of PDGF $\beta$ receptor phosphorylation among the coronary risk factors and clinical events was unstable angina. The mean value of the extent of PDGF $\beta$ receptor tyrosine phosphorylation in DCA specimens from the patients with unstable angina was $1.43(0.98)$, which was significantly $(\mathrm{p}<0.002)$ higher than in specimens from the 39 patients with stable angina $(0.62(0.48)$ ) (fig $4)$.

\section{Discussion}

This study is the first to document tyrosine phosphorylation of PDGF $\beta$ receptor in vivo (a measure of PDGF $\beta$ receptor activation) in atherectomy specimens and in normal arteries. The three major findings in the present study are: PDGF $\beta$ receptor tyrosine phosphorylation in atherosclerotic lesions is increased compared with non-atherosclerotic arteries; the association of PDGF $\beta$ receptor tyrosine phosphorylation with immediate gain correlates with vascular remodelling after DCA; and among a number of coronary risk factors and clinical events examined, unstable angina is significantly associated with the increased extent of PDGF $\beta$ receptor tyrosine phosphorylation.

The observation of that the extent of tyrosine phosphorylation of PDGF $\beta$ receptor was increased in most specimens from atherosclerotic lesions of coronary arteries compared with non-atherosclerotic internal thoracic arteries implies increased local activity of PDGF in 
atherosclerotic plaques. In atherosclerotic lesions, PDGF $\mathrm{B}$ chain, a preferred ligand for PDGF $\beta$ receptor, was reported to be produced and released from infiltrating monocytes/ macrophages, endothelium, and/or adhering platelets. ${ }^{28}$ The local release of PDGF B chain at atherosclerotic lesions is presumably increased in patients with greater phosphorylation of PDGF $\beta$ receptor in atherectomy specimens. The observed tyrosine phosphorylation of PDGF $\beta$ receptor is unlikely to be caused by the DCA procedure itself, because we found no correlation between PDGF $\beta$ receptor tyrosine phosphorylation and immediate gain of the lumen diameter. Locally released PDGF is very likely an important growth factor leading to the intimal proliferative response in the injured vascular wall. Increased local release of PDGF in injured stenotic lesions could cause augmented proliferation. Moreover, it is reported that there are compensatory enlargement mechanisms associated with neointimal formation after coronary interventions, and this geometric remodelling is important to luminal narrowing after PTCA. ${ }^{6}$ One explanation for this observation is that PDGF increases the cytosolic free calcium concentration and causes a concentration dependent contraction of the artery. ${ }^{14}$ Thus, it appears reasonable to conclude that greater PDGF activity prevents the enlargement mechanism of vascular remodelling and contributes to restenosis after PTCA.

It was previously demonstrated that the amount of immediate gain of lumen diameter after a coronary intervention correlates with the amount of late loss of lumen diameter. ${ }^{26}{ }^{27}$ The results of the present study revealed that the extent of PDGF $\beta$ receptor tyrosine phosphorylation also correlated with the amount of late loss of lumen diameter, although weaker than immediate gain of lumen diameter (fig 3A and B). It is now generally recognised that although late loss increases with immediate gain of lumen diameter, increased immediate gain still produces a net beneficial effect of reducing restenosis because the amount of late loss is only a fraction of the amount of immediate gain. ${ }^{26}{ }^{27}$ However, it is still difficult to predict the probability of restenosis for individual patients based on a large immediate gain result alone, because of the presence of multiple other biological influences on restenosis. The data in this study may suggest that the local PDGF activity reflected by the tyrosine phosphorylation level of PDGF $\beta$ receptor in atherectomy specimens is one biological influence on restenosis. The observation that PDGF $\beta$ receptor phosphorylation and immediate gain correlated better with angiographic late loss than either PDGF $\beta$ receptor tyrosine phosphorylation or immediate gain alone (fig $3 \mathrm{C}$ ) supports this notion.

Although we could not accurately measure the amount of PDGF $\beta$ receptor protein by western blotting, we believe that PDGF $\beta$ receptor tyrosine phosphorylation, as measured by phosphotyrosine content of immunoprecipitated PDGF $\beta$ receptors, is an accurate predictor of total PDGF $\beta$ receptor activity for several reasons: tissue PDGF $\beta$ receptor number is a critical determinant of PDGF mediated activity and receptor immunoprecipitation has been determined to be quantitative (table 1) ${ }^{20}$; after PDGF ligand binding to the PDGF $\beta$ receptor, receptor activation occurs by tyrosine phosphorylation of the receptor. ${ }^{30}$ Thus, the phosphotyrosine content of the PDGF $\beta$ receptor reflects tissue PDGF $\beta$ receptor "activation". Therefore, phosphotyrosine content of the PDGF $\beta$ receptor is a better predictor of tissue PDGF $\beta$ receptor activity as it reflects both receptor number and activation by PDGF-ligand binding. As equal quantities of protein from DCA samples were analysed for PDGF $\beta$ receptor phosphotyrosine content, the phosphotyrosine levels of PDGF $\beta$ receptors in these samples are an accurate correlate of vascular remodelling and clinical events. By applying a similar technique to rat carotid balloon injury model, we recently observed that PDGF $\beta$ receptor tyrosine phosphorylation is increased during the growing phase of the neointima and that suppression of neointima formation is accompanied by a decrease in PDGF $\beta$ receptor tyrosine phosphorylation. ${ }^{20}$

It is important to emphasise that the extent of PDGF $\beta$ receptor activation in atherectomy specimens from patients with unstable angina was higher than in those from patients with stable angina (fig 4). Numerous clinical, anatomical, and procedural variables have been proposed as predictors of restenosis after successful PTCA. ${ }^{2}$ Among the clinical variables, diabetes mellitus and unstable angina have been mentioned most frequently. ${ }^{2}$ However, few studies have addressed the molecular mechanisms of the restenosis process in unstable angina. Angiography, ${ }^{31}$ angioscopy, ${ }^{32}$ and histological studies ${ }^{33}$ have demonstrated that the most important pathological feature of unstable angina is coronary thrombosis. Plaque disruption resulting in platelet activation, aggregation, and subsequent thrombus formation are highly associated with unstable angina and acute myocardial ischaemia. Moreover, thrombi are rich in platelets and monocytes/ macrophages, both of which are associated with the biological activities of PDGF in the vascular wall. ${ }^{28}$ In addition, recently it has been reported that increasing amounts of macrophages have been detected in the plaque shoulder regions of histological sections from patients with acute coronary syndromes. ${ }^{34}$ Therefore, PDGF released by platelets in coronary thrombi and macrophages in plaque walls may activate vascular PDGF $\beta$ receptor and therefore be responsible, at least in part, for the association between unstable angina and restenosis after a percutaneous transluminal coronary intervention.

This study was intentionally limited to describing an important new relation between the loss index and PDGF $\beta$ receptor tyrosine phosphorylation, regardless of whether the lesions were de novo or restenotic. In interpreting our findings, several limitations need to be mentioned. First, the mechanism of restenosis may differ in patients with unstable and stable angina, and in de novo and restenotic lesions. However, Kuntz et $a l^{27}$ have reported that the 
late loss in lumen diameter varied directly with immediate gain, although they include $41 \%$ prior restenosis lesions in their study population. Another limitation is that we could not accurately measure the level of PDGF $\beta$ receptor protein by western blotting due to the limited amount of protein. However, as equal amounts of total protein from DCA and LITA control samples were analysed, we believe that PDGF $\beta$ receptor phosphotyrosine content represents tissue PDGF $\beta$ receptor activation and reflects PDGF $\beta$ receptor expression. Finally, the angiographic follow up varied from two to eight months, because patients who underwent earlier restenosis ( $<4$ months) had to be restudied at that time for the evaluation of recurrent symptoms, and this could contribute to the variability of this study.

The authors gratefully acknowledge the valuable technical and secretarial assistance of N Miyamoto, E Kishimoto, and Yamazaki. We are grateful to J Tanaka, I Kikawa, S Fukuda, H Suma, and Y Wanibuchi for helping to deal with internal thoracic arteries, and to $\mathrm{N}$ Yamaguchi and $\mathrm{T}$ Mizuhara for checking the statistical analysis. Many thanks to A S Baas, and B C Berk for critical reading of the manuscript. We also thank T Isshiki, $M$ Kashida, and T Yamaguchi for their informative discussion and guidance. This work was supported by grants from the Ministry of Education, Science and Culture of Japan, fund for cardiovascular research from Tsumura Co, and funds from Japan Heart Foundation and Japan Research Foundation for Clinical Pharmacology.

1 Hirshfeld JW Jr, Schwartz JS, Jugo R, et al. Restenosis after coronary angioplasty: a multivariate statistical model to relate lesion and procedure variables to restenosis. The M-HEART Investigators. $\mathcal{F}$ Am Coll Cardiol 1991;18:64756.

Landau C, Lange RA, Hillis LD. Percutaneous transluminal coronary angioplasty. N Engl f Med 1994;330:981-93.

3 Glagov S. Intimal hyperplasia, vascular modeling, and the restenosis problem. Circulation 1994;89:2888-91.

4 Safian RD, Gelbfish JS, Erny RE, et al. Coronary atherectomy. Clinical, angiographic, and histological findings and observations regarding potential mechanisms. Circulation 1990;82:69-79.

5 Glagov S, Weisenberg E, Zarins CK, et al. Compensatory enlargement of human atherosclerotic coronary arteries. $N$ Engl $\mathcal{F}$ Med 1987;316:1371-5.

6 Kimura T, Kaburagi S, Tashima Y, et al. Geometric remodeling and intimal regrowth as mechanisms of restenosis: observation from serial ultrasound analysis of restenosis (SURE) trial [abstract]. Circulation 1995;92 (suppl I):I-76.

7 Libby P, Warner SJ, Salomon RN, et al. Production of platelet-derived growth factor-like mitogen by smoothmuscle cells from human atheroma. $N$ Engl $\mathcal{F}$ Med 1988;318:1493-8.

8 Lindner V, Reidy MA. Proliferation of smooth muscle cells after vascular injury is inhibited by an antibody against basic fibroblast grou

9 Majesky MW, Lindner V, Twardzik DR, et al. Production of transforming growth factor beta 1 during repair of arterial injury. $\mathcal{F}$ Clin Invest 1991;88:904-10.

10 Powell JS, Clozel JP, Muller RK, et al. Inhibitors of angiotensin-converting enzyme prevent myointimal proliferation after vascular injury. Science 1989;245:186-8

11 Cercek B, Fishbein MC, Forrester JS, et al. Induction of insulin-like growth factor I messenger RNA in rat aorta after balloon denudation. Circ Res 1990;66:1755-60.

12 Ross R, Masuda J, Raines EW, et al. Localization of PDGF-B protein in macrophages in all phases of atherogenesis. Science 1990;248:1009-12.
13 Wilcox JN, Smith KM, Williams LT, et al. Platelet-derived growth factor mRNA detection in human atherosclerotic plaques by in situ hybridization. F Clin Invest 1988;82: $1134-43$.

14 Berk BC, Alexander RW, Brock TA, et al. Vasoconstriction: a new activity for platelet-derived growth factor. Science 1986;232:87-90.

15 Barrett TB, Benditt EP. Platelet-derived growth factor gene expression in human atherosclerotic plaques and normal artery wall. Proc Natl Acad Sci USA 1988;85:2810-14.

16 Rubin K, Tingstrom A, Hansson GK, et al. Induction of B-type receptors for platelet-derived growth factor in vascular inflammation: possible implications for development of vascular proliferative lesions. Lancet 1988;i: 1353-6.

17 Heldin $\mathrm{CH}$. Structural and functional studies on plateletderived growth factor. EMBO f 1992;11:4251-9.

18 Seifert RA, Hart CE, Phillips PE, et al. Two different subunits associate to create isoform-specific platelet-derived growth factor receptors. F Biol Chem 1989;264:8771-8.

19 Sachinidis A, Schulte K, Ko Y, et al. The induction of early response genes in rat smooth muscle cells by PDGF-AA is not sufficient to stimulate DNA-synthesis. FEBS Lett 1993;319:221-4.

20 Abe J, Deguchi J, Matsumoto T, et al. Stimulated activation of platelet-derived growth factor receptor in vivo in balloon-injured arteries-a link between angiotensin II and intimal thickening. Circulation 1997;96:1906-13.

21 Simpson JB, Selmon MR, Robertson GC, et al. Transluminal atherectomy for occlusive peripheral vascular disease. Am f Cardiol 1988;61:96G-101G.

22 Simons M, Leclerc G, Safian RD, et al. Relation between activated smooth-muscle cells in coronary-artery lesions and restenosis after atherectomy. N Engl f Med 1993;328: 608-13.

23 Pickering JG, Weir L, Jekanowski J, et al. Proliferative activity in peripheral and coronary atherosclerotic plaque among patients undergoing percutaneous revascularization. $\mathcal{F}$ Clin Invest 1993;91:1469-80.

24 Abe J, Zhou W, Takuwa N, et al. A fumagillin derivative angiogenesis inhibitor, AGM-1470, inhibits activation of cyclin-dependent kinases and phosphorylation of retinoblastoma gene product but not protein tyrosyl phosphorblastoma gene product but not protein tyrosyl phosphorylation or protooncogene expression
cells. Cancer Res 1994;54:3407-12.

25 Scoblionko DP, Brown BG, Mitten S, et al. A new digital electronic caliper for measurement of coronary arterial stenosis: comparison with visual estimates and computerassisted measurements. Am f Cardiol 1984;53:689-93.

26 Kuntz RE, Gibson CM, Nobuyoshi M, et al. Generalized model of restenosis after conventional balloon angioplasty, stenting and directional atherectomy. $\mathrm{f} \mathrm{Am}$ Coll Cardiol 1993;21:15-25.

27 Kuntz RE, Safian RD, Carrozza JP, et al. The importance of acute luminal diameter in determining restenosis after coronary atherectomy or stenting. Circulation 1992;86: $1827-35$.

28 Heldin $\mathrm{CH}$. Dimerization of cell surface receptors in signal transduction. Cell 1995;80:213-23.

29 Ross R. The pathogenesis of atherosclerosis: a perspective for the 1990s. Nature 1993;362:801-9.

30 Kazlauskas A, Cooper JA. Autophosphorylation of the PDGF receptor in the kinase insert region regulates interactions with cell proteins. Cell 1989;58:1121-33.

31 Rehr R, Disciascio G, Vetrovec G, et al. Angiographic morphology of coronary artery stenoses in prolonged rest angina: evidence of intracoronary thrombosis. $7 \mathrm{Am}$ Coll Cardiol 1989;14:1429-37.

32 Mizuno K, Miyamoto A, Satomura K, et al. Angioscopic coronary macromorphology in patients with acute coronary disorders. Lancet 1991;337:809-12.

33 Falk E. Unstable angina with fatal outcome: dynamic coronary thrombosis leading to infarction and/or sudden death. Autopsy evidence of recurrent mural thrombosis with peripheral embolization culminating in total vascular occlusion. Circulation 1985;71:699-708.

34 Moreno PR, Falk E, Palacios IF, et al. Macrophage infiltration in acute coronary syndromes. Implications for plaque rupture. Circulation 1994;90:775-8. 